\title{
(E)merging directions on air pollution and climate change research in Mediterranean Basin ecosystems
}

\author{
Silvana Munzi ${ }^{1}$ (D) $\cdot$ Raúl Ochoa-Hueso $^{2} \cdot$ Giacomo Gerosa $^{3} \cdot$ Riccardo Marzuoli $^{3}$
}

Received: 31 October 2017 / Accepted: 3 November 2017

(C) Springer-Verlag GmbH Germany, part of Springer Nature 2017

More than 150 years of massively poisoning our atmosphere and altering the global climate in the name of progress has already taken a big planetary toll in terms of human and ecosystem health. In fact, air pollution and extreme weather events currently cause the sickening and premature death of ca. half-million people in the European Union every year (D'Amato et al. 2013; De Sario et al. 2013; EEA 2016). Many experts agree in that we have now probably arrived at a crucial point where we need to decisively act to prevent an even bigger, possibly irreversible, global environmental and humanitarian catastrophe (IPCC 2014). An action that, at the Mediterranean Basin level, is currently being coordinated by the Union for the Mediterranean (http://ufmsecretariat.org/), an intergovernmental institution that brings together countries to promote dialog and cooperation in the EuroMediterranean region. However, political actions and societal goals also need to be grounded on sound scientific knowledge, a demand that the Mediterranean community of environmental scientists could satisfy through CAPERmed (Conference on Air Pollution Effects Research on Mediterranean Ecosystems; http://capermed.weebly.com/).

Responsible editor: Philippe Garrigues

Silvana Munzi

ssmunzi@fc.ul.pt

1 Centre for Ecology, Evolution and Environmental Changes, Faculdade de Ciências da Universidade de Lisboa, Campo Grande, 1749-016 Lisbon, Portugal

2 Departamento de Ecología, Universidad Autónoma de Madrid, 2, Darwin Street, 28049 Madrid, Spain

3 Department of Mathematics and Physics, Catholic University of Brescia, Via dei Musei 41, Brescia, Italy
The first CAPERmed meeting was celebrated in 2014 in Lisbon, Portugal, in order to coordinate regional air pollution and climate change expertise with the double aim of (1) quantifying current impacts and (2) identifying future challenges. As a result of the first meeting, we gathered all the available information and wrote a synthesis article where we reviewed the ecological impacts of air pollution and its interactions with climate change in the Mediterranean region (Ochoa-Hueso et al. 2017a). The second CAPERmed meeting, celebrated in 2016 in Brescia, Italy, also had a double aim. First, we used all the information previously gathered to propose a way forward, putting the emphasis on novel approaches to tackle a question (i.e., air pollution in the Mediterranean Basin) that has been around for a long time. The second goal was to keep promoting CAPERmed as a glue platform where the Mediterranean scientific community could keep sharing impressions and experiences and to merge, so to speak, our directions so we could all work to reach a common, greater goal, and hence the title of the editorial that introduces a special issue with the homonym title, "(E)merging directions on air pollution and climate change research in Mediterranean Basin ecosystems," which refers to both the novelty of aspects and the confluence of goals.

The first question that might come to the mind of the accidental reader is, of course, why focus specifically on Mediterranean ecosystems? Mediterranean ecosystems are particularly biodiverse and include iconic ecosystems that share an evolutionary origin with human populations back to the commencement of the Neolithic. These ecosystems include the Spanish dehesas and Portuguese montados and provide key supporting, provisioning, and cultural services upon which the Mediterranean populations greatly rely. However, natural and man-made Mediterranean ecosystems are currently threatened by air pollution and climate change. Air pollution in the Mediterranean Basin is primarily in the form of 
particulate matter and ozone and nitrogen $(\mathrm{N})$ deposition (Ochoa-Hueso et al. 2017a). Other forms of air pollution prevalent in the Mediterranean include pollution by toxic metals, whose consequences for human health are particularly worrisome. Toxic metal pollution is often linked to lack of proper management of waste products, such as in the case of the triangle of death in Italy (Senior and Mazza 2004). The impacts of atmospheric pollution and climate change can reverberate throughout the whole ecosystem and thus a multidisciplinary approach is needed, from soils and microbes to plants and soil fauna and from community-level analyses to physiological evaluations in response to pollutant exposure. A multidisciplinary approach that is patent in this special issue, which opens with two articles (Lo Cascio et al. 2017; Ochoa-Hueso et al. 2017b) that focus primarily on the response of Mediterranean soils and soil-inhabiting communities to $\mathrm{N}$ deposition, is followed by three articles that focus on the usefulness of cryptogams (mosses, lichens, and liverworts) as biomarkers of increasing aridity and toxic metal pollution (Basile et al. 2017; Cogolludo et al. 2017; Paoli et al. 2017). The issue continues with two articles by Avila et al. (2017) and Cabal et al. (2017) about the patterns and effects of nitrogen deposition on woody plant-dominated ecosystems from Spain and finishes with three articles focused on the effects of tropospheric ozone on larch forests (Finco et al. 2017), crops (Marzuoli et al., 2016), and pasture species (GonzálezFernández et al. 2017).

Soil is a crucial part of all the terrestrial ecosystems and a particularly complex one. Healthy soils provide plants with an adequate supply of nutrients and harbor highly diverse communities of microbes and micro- and macro-fauna that form a complex network of trophic and non-trophic interactions responsible for the adequate functioning of soils. Soils also store huge amounts of carbon, more than the living and atmospheric compartments together (Post et al. 1982), and can shift from being a net source or sink of carbon depending on environmental conditions, including those affected by human activities. Atmospheric $\mathrm{N}$ deposition, for example, can alter these source-sink dynamics by influencing net $\mathrm{CO}_{2}$ fluxes, particularly soil respiration. Despite the relevance of clarifying if $\mathrm{N}$ deposition-induced soil carbon sequestration can mitigate climate change and how that is regulated, in Mediterranean ecosystems the effects of $\mathrm{N}$ addition on soil respiration have so far been scarcely investigated. Carrying out experimental work at two semi-arid Mediterranean sites, one in Italy and one in Spain, Lo Cascio et al. (2017) found that respiration increased at the Italian site, a coastal macchia, while it decreased at the Spanish site, a continental rosemary shrubland, under simulated $\mathrm{N}$ deposition scenarios, suggesting that not only the dose and duration of $\mathrm{N}$ supply but also vegetation cover and seasonality of precipitations determine the soil response to $\mathrm{N}$ addition. Based on these results, the authors claim that there is a need to create a network of experimental sites in
Mediterranean countries due to the heterogeneity of Mediterranean environments and the variability of the responses. In fact, the NitroMed network introduced by Lo Cascio et al. (2017) represents a first attempt to achieve this.

The primary role of soils in the ecosystem response to $\mathrm{N}$ addition does not surprise if we think the disproportionately important role that biocrusts play in processes occurring in semi-arid ecosystems, where they provide many different ecosystem services. On the other hand, biocrusts themselves are very sensitive to global change drivers, which threatens their contribution to ecosystem health. In another study from this issue, Ochoa-Hueso et al. (2017a) investigated the impacts of 5 years of simulated $\mathrm{N}$ deposition on biocrust community composition, abundance, and soil photosynthetic and photoprotective pigment content in a semi-arid Mediterranean shrubland in Spain. They found that lichen cover decreased up to $50 \%$ compared to control conditions while moss cover did not change in response to $\mathrm{N}\left(10,20\right.$, and $\left.50 \mathrm{~kg} \mathrm{~N} h a^{-1} \mathrm{year}^{-1}\right)$. However, drivers such as soil $\mathrm{pH}$, organic matter content, and shrub cover were more relevant than $\mathrm{N}$ addition in determining composition and dynamics of the biocrust community, cyanobacterial abundance, and soil pigment concentration. These results again support the key role of environmental heterogeneity modulating the response of Mediterranean ecosystems to $\mathrm{N}$ deposition, and possibly to other global change drivers such as climate change. In agreement with this sensitivity of biocrust-forming lichens to global change, another study in this issue conducted in rural/ forested sites of Southern Portugal (Paoli et al. 2017) showed that the physiological response of foliose and fruticose terricolous lichens changed along an aridity gradient, and that the response was influenced by substrate requirements while growth form was not relevant, suggesting that biocrusts may be negatively affected in a future drier climate.

Due to their sensitivity to air pollution and climate change, cryptogams are often used as indicators of atmospheric pollution. Toxic metals very often represent an important fraction of pollutant emissions to the atmosphere and a very deleterious one in terms of human health and so cryptogams, particularly mosses, have been frequently proposed as earlywarning biomonitors of heavy metal pollution. In this issue, Cogolludo et al. (2017) investigated the response of three common Mediterranean bryophyte species to lead exposure. The species were chosen according to their previously reported tolerance level to metals: Tortula muralis (reported as tolerant to toxic metals), Syntrichia ruralis (medium-tolerant), and Tortula subulata (less tolerant). In contrast to expectations, their results showed a clear effect on growth parameters only at very high concentrations of lead, suggesting a limited value for these species as bioindicators of lead deposition. Interestingly, using histochemical analyses and scanning electron microscopy combined with energy dispersive $\mathrm{X}$-ray spectroscopy, the authors identified the existence of a lead exclusion strategy mediated by mucilage that could have been 
responsible for the observed tolerance. Another study in this issue used Lunularia cruciata, a tolerant liverwort species to identify parameters usable as biomarkers for environmental pollution in urban environments (Basile et al. 2017). Samples were collected in one of the three vertices of the socalled Italian Triangle of Death, a region in Italy known for being subject to unusually high levels of pollution associated with unregulated disposal of toxic waste. The authors observed ultrastructural damages by transmission electron microscopy and these were correlated to vitality, photosynthetic efficiency, heat shock proteins 70 (Hsp70) induction, and gene expression levels and chlorophyll degradation. A significant increment in Hsp70s expression and occurrence and modifications in the chloroplasts ultrastructure were considered promising parameters.

Nitrogen pollution is also a threat to ecosystems dominated by woody vegetation. However, many gaps still exist in our scientific knowledge that prevent the establishment of ecology-based policies to protect these environments. The role of the interactions between the canopy and $\mathrm{N}$ pollutants is one of them. In this issue, Avila et al. (2017) measured N deposition (as bulk, wet, and throughfall fluxes of dissolved inorganic N) and air N gas concentrations from 2011 to 2013 at four Spanish holm-oak (Quercus ilex) sites characterized by different land use. The results showed that canopies retained both $\mathrm{NH}_{4}-\mathrm{N}$ and $\mathrm{NO}_{3}-\mathrm{N}$, with a higher retention at the agricultural and rural sites than at sites located close to big cities, highlighting the role of the forest canopy in processing $\mathrm{N}$ pollutant emissions. Shrublands are another widely distributed ecosystem type in biodiverse Mediterranean landscapes, where shrubs play a key role as nurse plants. The disappearance of shrublands caused by $\mathrm{N}$ deposition may accelerate the biodiversity loss associated with other global change drivers, hamper the recruitment of seedlings of woody species, and accelerate desertification processes. In this issue, Cabal et al. (2017) investigated the effects of N deposition and phosphorus fertilization on the dynamics of a Mediterranean rosemary shrubland in Central Spain and showed that $\mathrm{N}$ addition loads above $10 \mathrm{~kg} \mathrm{~N} \mathrm{ha}^{-1}$ year $^{-1}$ reverted the natural expanding dynamics of shrub cover in the area. However, this effect was not associated with the inhibition of the growth of young shoots but rather by a reduction of leaf lifespan, which the authors suggest could have been triggered by toxicity effects derived from long-term $\mathrm{N}$ accumulation in old leaves.

The other major pollutant threating Mediterranean vegetation is ozone. Finco et al. (2017) assessed ozone risk in larch forests that are predicted to be impacted by climate change in the next decades by comparing ozone exposure (as $\mathrm{AOT}_{40}$ ) and direct measurements of the stomatal ozone flux during 2 consecutive years. The results suggest that climate change will likely affect the health status of treeline forests. The effects of ozone were tested also on plants of economic relevance.
Marzuoli et al. (2016) investigated the response in terms of yield reduction of two lettuce (Lactuca sativa) cultivars under two different levels of ozone using open-top chambers under Mediterranean conditions. The authors reported a critical level of $1 \mathrm{mmol} \mathrm{O}_{3} \mathrm{~m}^{-2}$ of phytotoxic ozone dose for a $15 \%$ of marketable yield loss for both the lettuce cultivars, drawing attention to the high sensitivity of this horticultural crop. In another study, González-Fernández et al. (2017) tested the recently established $\mathrm{O}_{3}$ critical levels for annual Mediterranean pasture species (Trifolium). In fact, while plants growing in well-watered pots at a coastal site and under low levels of competition were used to establish the critical levels, a validation in different conditions was missing. The authors cultivated the same species in a continental site, in natural soil, under water stress and inter-specific competition, representing more closely the natural habitat of the species. The results confirmed the validity of applying the current fluxbased $\mathrm{O}_{3}$ critical level under close-to-natural growing conditions, but authors recommend further experiments considering complex inter-specific competition and the effect of synergies with other factors such as $\mathrm{N}$ pollution.

The abovementioned studies are just a slice of the ongoing research focused on the response of Mediterranean Basin ecosystems to climate change and air pollution. However, it is becoming clear that there is a growing need to extend these investigations within a common and integrated network. A possible future direction could be the development of a network of coordinated manipulation experiments in different Mediterranean countries and/or studies along wide environmental and air pollution gradients. Particular consideration should also be dedicated to multiple stresses simultaneously and their interaction, moving from the study of the effects on single species to the effects at ecosystem level (including competition, biodiversity, biogeochemical cycles). This network could be the basis of a collaborative project aimed at the adoption of common, innovative methodologies for monitoring and assessment of climate change and air pollution effects in the Mediterranean ecosystems. Moreover, projects aimed at raising people awareness on these problems through educational and outreach activities are advisable. These topics will be the subject of the next CAPERmed meeting that will be held in Pamplona (Spain) in June 2018. For further information and updates, please visit the webpage.

\section{References}

Avila A, Aguillaume L, Izquieta-Rojano S, García-Gómez H, Elustondo D, Santamaría JM, Alonso R (2017) Quantitative study on nitrogen deposition and canopy retention in Mediterranean evergreen forests. Environ Sci Pollut Res. https://doi.org/10.1007/s11356-017-8861-4

Basile A, Loppi S, Piscopo M et al (2017) The biological response chain to pollution: a case study from the Italian "triangle of death" 
assessed with the liverwort Lunularia cruciata. Environ Sci Pollut Res. https://doi.org/10.1007/s11356-017-9304-y

Cabal C, Ochoa-Hueso R, Pérez-Corona ME, Manrique E (2017) Longterm simulated nitrogen deposition alters the plant cover dynamics of a Mediterranean rosemary shrubland in Central Spain through defoliation. Environ Sci Pollut Res. https://doi.org/10.1007/ s11356-017-8879-7

Cogolludo J, Estébanez B, Medina NG (2017) The effects of experimentally supplied lead nitrate on three common Mediterranean moss species. Environ Sci Pollut Res. https://doi.org/10.1007/s11356-017-9220-1

D’Amato G, Baena-Cagnani CE, Cecchi L, Annesi-Maesano I, Nunes C, Ansotegui I, D'Amato M, Liccardi G, Sofia M, Canonica WG (2013) Climate change, air pollution and extreme events leading to increasing prevalence of allergic respiratory diseases. Multidiscip Respir Med 8(1):12

De Sario M, Katsouyanni K, Michelozzi P (2013) Climate change, extreme weather events, air pollution and respiratory health in Europe. Eur Respir J 42(3):826-843

European Environment Agency (2016) Air quality in Europe - 2016 report. https://www.eea.europa.eu/publications/air-quality-ineurope-2016. Accessed 08 October 2017

Finco A, Marzuoli R, Chiesa M, Gerosa G (2017) Ozone risk assessment for an Alpine larch forest in two vegetative seasons with different approaches: comparison of $\mathrm{POD}_{1}$ and $\mathrm{AOT}_{40}$. Environ Sci Pollut Res. https://doi.org/10.1007/s11356-017-9301-1

González-Fernández I, Sanz J, Calvete-Sogo H, Elvira S, Alonso R, Bermejo-Bermejo V (2017) Validation of ozone response functions for annual Mediterranean pasture species using close-to-fieldconditions experiments. Environ Sci Pollut Res. https://doi.org/10. 1007/s11356-017-9099-x

Intergovernmental Panel on Climate Change (2014) Synthesis Report. http://ar5-syr.ipcc.ch/. Accessed 08 October 2017

Lo Cascio M, Morillas L, Ochoa-Hueso R et al (2017) Contrasting effects of nitrogen deposition on soil respiration in two Mediterranean ecosystems. Environ Sci Pollut Res. https://doi.org/10.1007/s11356-017-8852-5

Marzuoli R, Finco A, Chiesa M, Gerosa G (2016) A dose-response relationship for marketable yield reduction of two lettuce (Lactuca sativa L.) cultivars exposed to tropospheric ozone in Southern Europe. Environ Sci Pollut Res. https://doi.org/10.1007/s11356-016-8224-6

Ochoa-Hueso R, Munzi S, Alonso R et al (2017a) Ecological impacts of atmospheric pollution and interactions with climate change in terrestrial ecosystems of the Mediterranean Basin: current research and future directions. Environ Pollut 227:194-206

Ochoa-Hueso R, Mondragon-Cortés T, Concostrina-Zubiri L, SerranoGrijalva L, Estebanez B (2017b) Simulated nitrogen deposition reduces lichen cover and soil pigment content in biocrusts from a Mediterranean shrubland. Environ Sci Pollut Res. https://doi.org/ 10.1007/s11356-017-0482-4

Paoli L, Pinho P, Branquinho C, Loppi S, Munzi S (2017) The influence of growth form and substrate on lichen ecophysiological responses along an aridity gradient. Environ Sci Pollut Res. https://doi.org/10. 1007/s11356-017-9361-2
Post WM, Emanuel WR, Zinke PJ, Stangenberger AG (1982) Soil carbon pools and world life zones. Nature 298:156-159

Senior K, Mazza A (2004) Italian "triangle of death" linked to waste crisis. Lancet Oncology 5(9):525-527

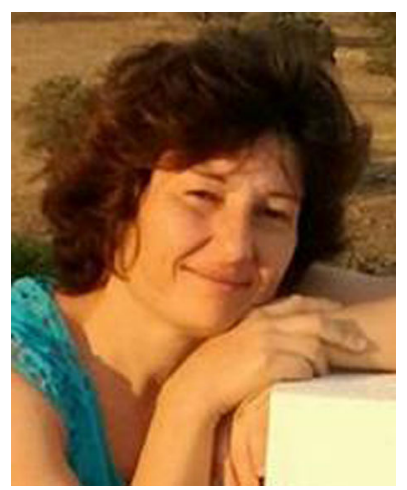

Dr. Silvana Munzi: Ph.D. has been a Research Assistant at the Centre for Ecology, Evolution and Environmental Changes, Universidade de Lisboa, since 2014. After working on the use of lichens as bioindicators and bioaccumulators, during her Ph.D., she started investigating eco-physiological parameters in lichens under nitrogen stress. Principal investigator and participant in several national and international projects focused on the impact of nitrogen on lichens, she was awarded a Marie Curie fellowship on the topic. Current research activity is focused on the study of symbiotic systems, namely lichens and mycorrhizae, from a molecular and physiological point of view, aiming at understanding the mechanisms responsible for their ability to cope with environmental stresses.

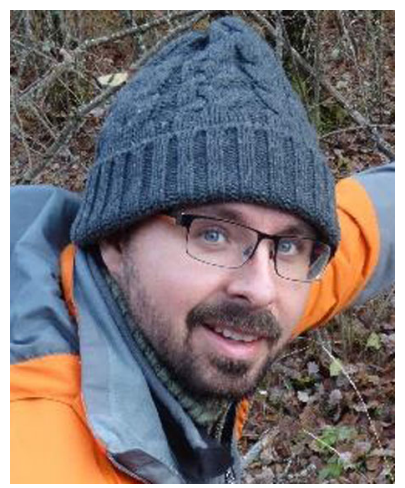

Dr. Raúl Ochoa-Hueso research interests focus in understanding the consequences of global environmental change drivers such as atmospheric nitrogen deposition and drought on soil and plant communities and aboveground-belowground interactions, particularly in the context of Mediterranean-type ecosystems. He is also interested in understanding how these undesired, negative impacts affect key ecosystem services such as soil fertility and aboveground and belowground carbon storage and, in the last term, human welfare. Dr. Ochoa-Hueso is highly committed to disseminating his scientific results to a wider public to contribute to raise the societal awareness about these environmental threats. 


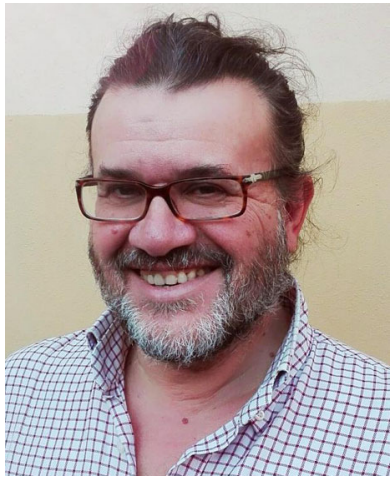

Prof. Giacomo Al. Gerosa Professor of Atmospheric Physics (2015) and Ecology at the Catholic University of the S.H., Brescia (Italy), formerly researcher of Agricultural Chemistry (2006-2014). PhD Agricultural Ecology (2002), MSc Environmental Sciences (1997). Member of the faculty for the international $\mathrm{PhD}$ school of Science of the Catholic Universities of Milan (Italy), Leuven (Belgium), Notre Dame (USA) and Santiago (Chile), and of the PhD school on Natural Hazards of the University of Chieti (Italy). $\mathrm{PhD}$ and MSc supervisor. The main research interests are micrometeorology and gaseous exchange between vegetation and atmosphere as well as air pollution effects on vegetation, with particular regards to ozone and nitrogen oxides. Published more than 80 research papers in the last 15 years on peer-reviewed journals. Participated in several European and national research projects as Scientific Coordinator for the Catholic University, and in the activities of the International Cooperative Programme on Effects of Air Pollution on Natural Vegetation and
Crops (ICP Vegetation) established by the United Nations Economic Commission for Europe (UNECE). Member of the editorial board of five scientific journals on environmental topics. Currently, he coordinates the ANAPNOI Project on indoor air quality with special regards to particulate matter.

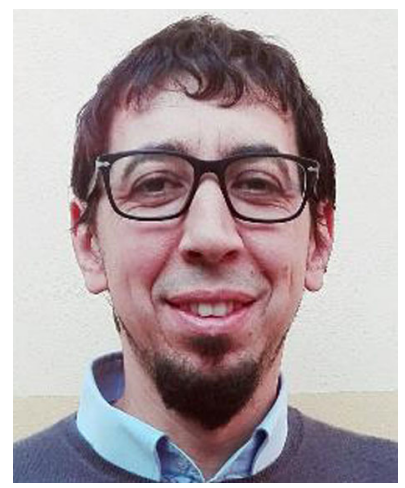

Dr. Riccardo Marzuoli: Ph.D. in crop ecology, major research fields include the evaluation of the impacts of air pollution and climate change on crops and forest ecosystems, with particular interest in the tropospheric ozone effects, and its interaction with other abiotic stresses. Published more than 40 research papers in the last 15 years on peerreviewed journals. Participated in several European and national research projects, and in the activities of the International Cooperative Programme on Effects of Air Pollution on Natural Vegetation and Crops (ICP Vegetation) established by the United Nations Economic Commission for Europe (UNECE). 